Marc Pawlitzki, MD

Jens Neumann, MD

Jörn Kaufmann, PhD

Jan Heidel

Erhard Stadler, MSc

Catherine Sweeney-Reed,

MBBS, PhD

Michael Sailer, MD

Stefanie Schreiber, MD

Correspondence to

Dr. Pawlitzki:

Marc.pawlitzki@med.ovgu.de
Supplemental data at Neurology.org/nn

\title{
Loss of corticospinal tract integrity in early MS disease stages
}

OPEN

\section{ABSTRACT}

Objective: We investigated corticospinal tract (CST) integrity in the absence of white matter (WM) lesions using diffusion tensor imaging (DTI) in early MS disease stages.

Methods: Our study comprised 19 patients with clinically isolated syndrome (CIS), 11 patients with relapsing-remitting MS (RRMS), and 32 age- and sex-matched healthy controls, for whom MRI measures of CST integrity (fractional anisotropy [FA], mean diffusivity [MD]), T1- and T2based lesion load, and brain volumes were available. The mean (SD) disease duration was 3.5 (2.1) months, and disability score was low (median Expanded Disability Status Scale 1.5) at the time of the study.

Results: Patients with CIS and RRMS had significantly lower CST FA and higher CST MD values compared with controls. These findings were present, irrespective of whether WM lesions affected the CST. However, no group differences in the overall gray or WM volume were identified.

Conclusions: In early MS disease stages, CST integrity is already affected in the absence of WM lesions or brain atrophy. Neurol Neuroimmunol Neuroinflamm 2017;4:e399; doi: 10.1212/ NXI.0000000000000399

\section{GLOSSARY}

aCST $=$ affected CST; CIS = clinically isolated syndrome; $\mathbf{C S T}=$ corticospinal tract; EDSS $=$ Expanded Disability Status Scale; $\mathbf{F A}=$ fractional anisotropy; $\mathbf{G M V}$ = gray matter volume; $\mathbf{M D}=$ mean diffusivity; naCST = not affected CST; $\mathbf{N A W M}=$ normal-appearing white matter; NBV = normalized brain volume; RIS = radiologically isolated syndrome; $\mathbf{R O I}=$ region of interest; $\mathbf{R R M S ~ = ~ r e l a p s i n g - r e m i t t i n g ~ M S ; ~ S P M ~ = ~ s t a t i s t i c a l ~ p a r a m e t r i c ~ m a p p i n g ; ~} \mathbf{W M}=$ white matter; $\mathbf{W M V}=$ WM volume.

MS is characterized by chronic demyelinating CNS white matter (WM) lesions that were diagnosed and monitored using structural MRI. ${ }^{1}$ The extent and spread of the lesions is not, however, associated with early neurologic symptoms nor with underlying disease progression. ${ }^{2}$

Recent postmortem studies examining patients with long-standing MS not only demonstrated T2-hyperintense WM lesions histologically characterized by demyelination and transected axons but also identified diffuse microscopic axonal damage within the normalappearing WM (NAWM). ${ }^{3,4}$ If NAWM alterations could be found in vivo, they would potentially provide a valuable tool for the earlier detection of disease activity, especially when focusing on functionally important WM tracts, e.g., corticospinal tract (CST).

Diffusion tensor imaging (DTI) has been demonstrated to provide superior sensitivity compared with T2-weighted MRI, for the in vivo detection and quantification of WM and axonal damage. $^{5}$ In the absence of new or enlarging T2-weighted lesions, only ongoing whole-brain atrophy, and not loss of axonal integrity, has thus far been suggested to be indicative of disease activity in MS. ${ }^{6}$ Further studies emphasizing the potential of DTI measures within the clinical setting are therefore required.

\footnotetext{
From the Department of Neurology (M.P., J.N., J.K., J.H., E.S., C.S.-R., S.S.), Otto von Guericke University; MEDIAN Klinik NRZ Magdeburg (M.S.), Affiliated Institute for Neurorehabilitation of the Otto von Guericke University; and German Center for Neurodegenerative Diseases (DZNE) within the Helmholtz Association (S.S.), Magdeburg, Germany.

Funding information and disclosures are provided at the end of the article. Go to Neurology.org/nn for full disclosure forms. The Article Processing Charge was funded by the authors.

This is an open access article distributed under the terms of the Creative Commons Attribution-NonCommercial-NoDerivatives License 4.0 (CC BY-NC-ND), which permits downloading and sharing the work provided it is properly cited. The work cannot be changed in any way or used commercially without permission from the journal.
} 
Until now, most DTI studies in MS have been performed in (1) patients having long-standing disease and (2) without taking account of concurrent WM lesions. Our aim was, therefore, to examine the axonal integrity of the CST within the NAWM compared with the tract integrity when affected by WM lesions at early MS disease stages.

METHODS Participants. This study involved 30 patients with clinically isolated syndrome (CIS, $\mathrm{n}=19)$ or relapsingremitting MS (RRMS, $\mathrm{n}=11$ ) according to the McDonald criteria $(2001)^{7}$ and 32 age- and sex-matched healthy controls without a history of neurologic or psychiatric disorders. The participants were consecutively recruited in the Department of Neurology, Otto von Guericke University Magdeburg, Germany.

Clinical disability was quantified using the Expanded Disability Status Scale (EDSS) ranging from 0 to 10 points, with higher values indicating worse function. ${ }^{8}$ Clinical evaluation of all patients was performed by 2 independent neurologists (M.P. and M.S.).

Standard protocol approvals, registrations, and patient consents. The study was approved by the local ethics committee of the Otto von Guericke University Magdeburg, Germany (No. 09/04), and all participants provided written informed consent.

MRI. Acquisition. Images were acquired using a neurooptimized 1.5-T GE Signa Horizon LX (General Electric Company, Milwaukee, WI) scanner with actively shielded magnetic field gradients (maximum amplitude $40 \mathrm{mTm}^{-1}$ ). For further details of the MR protocol comprising DTI measures, see the supplemental material at Neurology.org/nn.

\section{Figure 1 CST pathways affected or not affected by focal white matter lesions.}

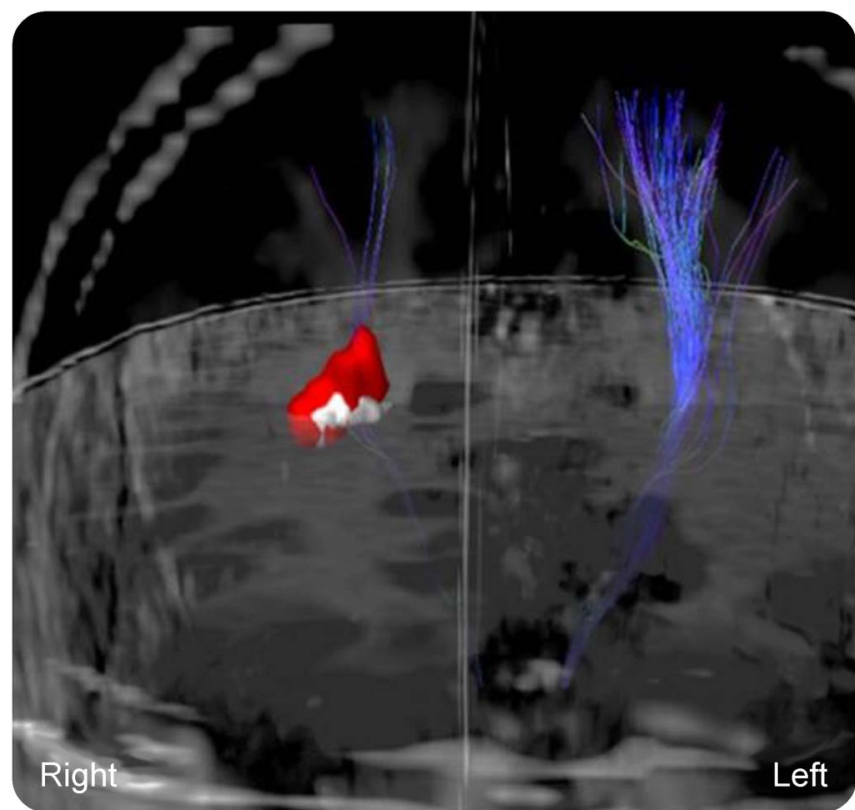

Pyramidal tracts (CST) in a 35-year-old male patient with clinically isolated syndrome (CIS) diagnosed two months ago (EDSS $=1$ ) are shown. In the right hemisphere, CST is affected by a white matter lesion (the T2-intense lesion is shown in red, the T1-intense overlapping lesion is demonstrated in white). CST proportions passing the lesion are demonstrated in blue (affected CST, aCST). Within the left hemisphere CST (in blue) is not affected by any white matter lesions (not affected CST, naCST).
CST integrity. The whole CST, between cortex and pons, was analyzed. First, 10 voxels of the CST were segmented at the level of the pons, using MRIcro and individual color-coded fractional anisotropy (FA) maps, to create a pons region of interest (ROI). Individual ROIs were exported, and fiber tract reconstruction was performed using a Monte Carlo simulation algorithm repeatedly searching for probable paths through the derived diffusion tensor matrix. ${ }^{9}$ Multiple tracking began in each preselected ROI voxel.

A fixed starting number of 50,000 fiber paths were computed for the CST for each ROI. For better visualization, single fibers were clustered according to the Euclidean distance of the path coordinates. All calculated paths were used sequentially for distance calculation. A path that could not be assigned to an existing cluster according to the distance criterion resulted in a new cluster. To select only the fibers of the CST, an additional filter (oval ellipse) was placed in the internal capsule. Only those clusters overlapping with this filter ROI were selected. The CST was then stored as a binary mask and exported for further processing.

Lesion segmentation. Lesion segmentation was performed on T1- and T2-weighted images using a semiautomated algorithm. Visual quality control of segmentation data was performed by 2 neurologists (M.P. and M.S.), and additional manual delineation was performed where necessary (see supplemental material). ROIs were then stored in a separate file and exported as binarized T1- and T2-lesion masks. ROI volume was taken as the sum of the volume of all lesions for a given participant and was calculated using statistical parametric mapping (SPM) software. CST and lesion masks were then coregistered and transformed using SPM.

Volumetric measures. The freely available software package Structural Imaging Evaluation with Normalization of Atrophy (SIENAX), as part of the FMRIB Software Library (FSL; fmrib.ox.ac.uk), was used to determine the brain tissue volume including the gray matter volume (GMV) of cortical and subcortical structures and the WM volume (WMV), and each was normalized against the participant's head size (normalized brain volume [NBV]).

Data analysis. CST and lesion masks were integrated to enable visual determination of whether CST fibers passed alongside lesions in each individual hemisphere of every patient (figure 1). Each hemisphere was examined separately. CST fibers that were affected by any lesion were classified as affected CST (aCST). In cases where CST fibers were unaffected by any lesion, the CST was defined as not affected CST (naCST).

For 3D-visualization, visual inspection and for FA and mean diffusivity (MD) measurements, MeVisLab (MeVis Medical Solutions AG and Fraunhofer MEVIS, Bremen, Germany) was used; analysis was performed by 1 rater (M.P.).

To assess whether FA or MD CST differed between the left and right hemispheres, an asymmetry index was calculated for each individual study participant. Calculation was performed as follows: asymmetry index $=\left(\mathrm{p}^{\mathrm{R}}-\mathrm{p}^{\mathrm{L}}\right) /\left(\mathrm{p}^{\mathrm{R}}+\mathrm{p}^{\mathrm{L}}\right)$ with $\mathrm{p}$ indicating the measure of interest (FA or MD), ${ }^{\mathrm{R}}$ indicating the right side, and ${ }^{\mathrm{L}}$ the left side. ${ }^{10}$ The index ranges between -1 and 1 , with values close to -1 or close to 1 indicating maximum asymmetry, whereas values close to 0 rule out FA and MD side differences. ${ }^{10}$

Statistical analysis. Statistical analysis was performed using SPSS 21 (IBM Corp., Armonk, NY). Left- and right-sided FA and MD CST values were averaged, as evaluation of the asymmetry index revealed no hemispheric differences (see Results for further details). An independent samples $t$ test and a MannWhitney $U$ test were performed to determine group differences 
between patients (with separate consideration of RRMS and CIS cases) and controls, taking account of FA, MD, NBV, GMV, WMV, and T1-/T2-lesion load. As 7 MRI outcome measures and 3 groups were considered, $p$ values $\leq 0.005(0.05 / 10)$ were deemed to be statistically significant.

An analysis of variance was subsequently conducted with leftor right-sided CST FA or MD as the respective dependent variable and group as the independent binary variable. Various groups were defined as follows: (1) left CST (controls, coded as 0 ) vs left aCST (patients, coded as 1), (2) left CST (controls, coded as 0) vs left naCST (patients, coded as 1), (3) left naCST (patients, coded as 0) vs left aCST (patients, coded as 1) or (4) right CST (controls, coded as 0 ) vs right aCST (patients, coded as 1), (5) right CST (controls, coded as 0 ) vs right aCST (patients, coded as 1), and (6) right naCST (patients, coded as 0 ) vs right aCST (patients, coded as 1). As $4 \mathrm{MRI}$ outcome measures and 6 groups were considered, $p$ values $\leq 0.005(0.05 / 10)$ were deemed to be statistically significant.

RESULTS The demographics of the cohort and the relevant clinical data are given in table 1 . Considering the whole patient group, $\mathrm{n}=20(66 \%)$ received standard immunomodulatory therapy agents, comprising interferon $\beta-1 \mathrm{a}$, interferon $\beta-1 \mathrm{~b}$, and glatiramer acetate (table 1). There were no age or sex differences between controls and patients in the separate analysis of the RRMS and CIS subgroups. In addition, disease duration, age at disease onset, and median EDSS did not differ between the CIS and RRMS cases.

Table 2 shows the imaging characteristics of the groups under investigation. No T1 or T2 lesions were identified in any of the healthy controls. Lesion volume did not differ between the RRMS and CIS subgroups. Moreover, NBV, GMV, and WMV did not differ significantly between the controls and the patient cohort.
In patients and controls, the asymmetry indices for FA and MD ranged from -0.02 to 0.00 , suggesting no significant differences between both hemispheres. The overall patient cohort, as well as the RRMS and CIS patient subgroups separately, had significantly lower CST FA values and significantly higher CST MD values compared with controls. The results remained largely unchanged when considering the leftand right-sided FA and MD values separately (table 2 and figure 2).

In 21 patients ( $\mathrm{n}=12$; CIS, $\mathrm{n}=9 \mathrm{RRMS})$, at least 1 CST was associated with WM lesions (aCST), resulting in 29 affected hemispheres. Of those 21 patients, in $\mathrm{n}=18$ ( $\mathrm{n}=12 \mathrm{CIS}, \mathrm{n}=6 \mathrm{RRMS})$, the left hemisphere was affected, whereas in $\mathrm{n}=11$ ( $n=6$ CIS, $n=5$ RRMS), the right hemisphere was affected. Compared with the CST in the controls, the aCST (of the patients) revealed significantly lower FA (for the left side only) and significantly higher leftand right-sided MD values. Left- and right-sided FA values were also lower in the naCST of the patients when compared with controls (figure 3 and table e-1).

DISCUSSION We aimed to investigate CST axonal integrity in the presence or absence of WM lesions using DTI in the very early stages following MS diagnosis. Our data revealed significant group differences between controls and patients (comprising RRMS and CIS) when considering cortical spinal tract FA and MD values, which were used to quantify axonal integrity loss. The findings did not depend on RRMS or CIS diagnosis. Group differences could not be further explained by other variables, including age, sex, or brain volume. In patients, axonal damage was

Table 1 Demographics and clinical data of the sample under consideration.

\begin{tabular}{|c|c|c|c|c|c|c|c|c|}
\hline & $\begin{array}{l}\text { Controls } \\
(\mathrm{N}=32)\end{array}$ & $\begin{array}{l}\text { Patients } \\
(\mathrm{N}=30)\end{array}$ & CIS (N = 19) & $\begin{array}{l}\text { RRMS } \\
(\mathrm{N}=11)\end{array}$ & $\begin{array}{l}p \text { Value, } \\
\text { controls } \\
\text { vs patients }\end{array}$ & $\begin{array}{l}\text { p Value, } \\
\text { controls } \\
\text { vs CIS }\end{array}$ & $\begin{array}{l}\text { p Value, } \\
\text { controls } \\
\text { vs RRMS }\end{array}$ & $\begin{array}{l}\text { p Value, CIS } \\
\text { vs RRMS }\end{array}$ \\
\hline Age, y & 34 [13.4] (20-60) & 30 [8.7] (16-45) & 32 [8.6] (16-43) & 28 [8.6] (18-45) & 0.2 & 0.5 & 0.1 & 0.2 \\
\hline Age at disease onset, $y$ & - & $30[8.5](16-44)$ & 32 [8.5] (16-43) & 27 [8.2] (18-44) & & & & 0.2 \\
\hline Disease duration, mo & - & 3.5 [2.1] (0-9) & $3.5[2.1](0-9)$ & 3.4 [2.2] (1-9) & - & - & - & 0.2 \\
\hline Treatment, n (\%) & - & $20(66)$ & $12(63)$ & $8(73)$ & - & - & - & 0.6 \\
\hline Interferon $\beta-1 \mathrm{a}$ IM, n (\%) & - & $16(53)$ & $10(53)$ & $6(55)$ & - & - & - & 0.5 \\
\hline Interferon $\beta-1 \mathrm{a}$ SC, $\mathrm{n}$ (\%) & - & $2(7)$ & $1(5)$ & 1 (9) & - & - & - & 0.5 \\
\hline Interferon $\beta$-1b SC, $\mathrm{n}$ (\%) & - & 1 (3) & 1 (5) & - & - & - & - & 0.5 \\
\hline
\end{tabular}

Abbreviations: $\mathrm{CIS}=$ clinically isolated syndrome; EDSS = Expanded Disability Status Scale; IM = intramuscular; $\mathrm{N}=$ number of participants; RRMS = relapsing-remitting MS; SC = subcutaneous.

Unless otherwise reported, mean [SD] (range) is given. Disease duration was defined as the time span between symptom onset and MRI. $p$ Values refer to subgroup comparisons; $p$ values of $\leq 0.05$ were deemed to be statistically significant; for continuous variables, a independent samples $t$ test or MannWhitney $U$ test was conducted, whereas for binary variables, a $\chi^{2}$ test was calculated. 


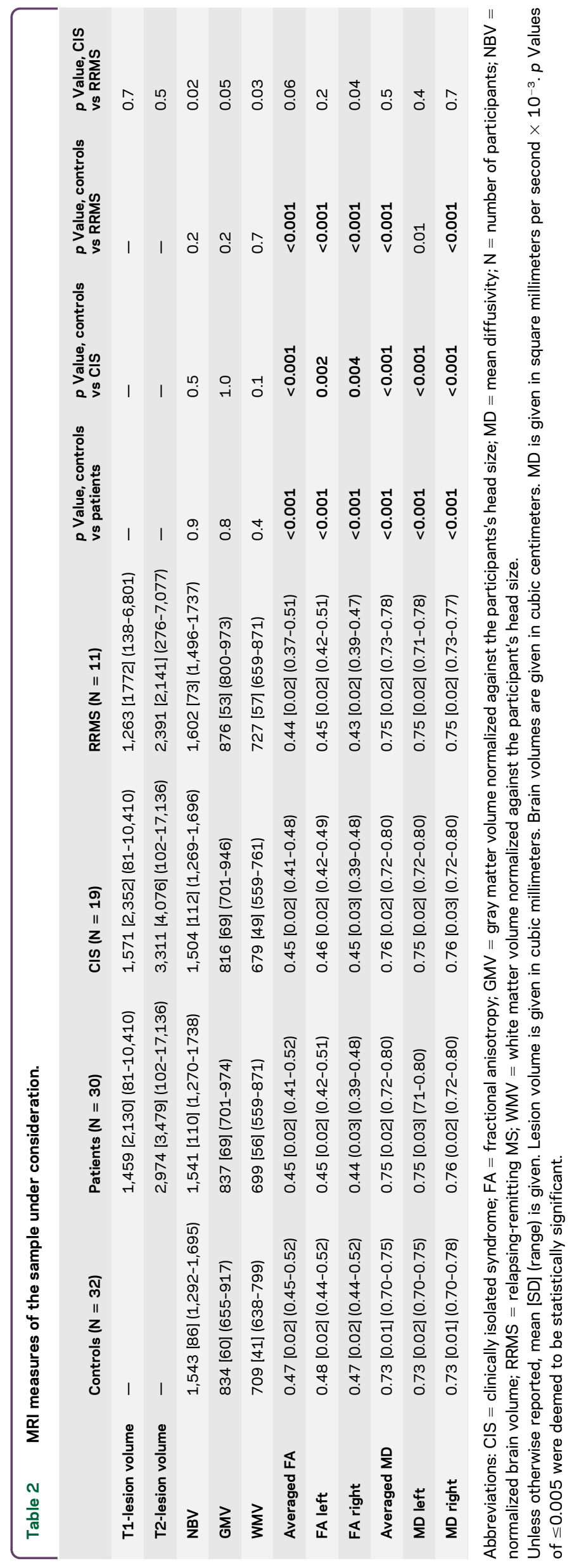

not only related to WM lesions, but was also detectable even in the normal-appearing WM. DTI measures should thus be considered as a promising tool for identifying subtle WM alterations in patients at very early MS disease stages.

Few NAWM DTI studies so far have been conducted in early MS disease variants, such as CIS. ${ }^{11,12}$ Most investigations have focused mainly on patients with MS having long-standing and progressive disease courses, only taking account of CST alterations within periventricular WM regions. ${ }^{13,14}$ In such studies, chronic MS seems to be related to an MD increase in the absence of FA alterations. ${ }^{15}$ An FA decrease thereby primarily occurs as a result of axonal demyelination, ${ }^{16}$ indicating WM integrity loss at early inflammatory disease stages. ${ }^{17}$ By contrast, MD alterations are mainly driven by increasing free space resulting from (1) early disease pathology, comprising vasogenic edema, astrocyte proliferation, or decreasing myelin content and (2) axonal or overall tissue loss/destruction occurring in longer-lasting disease. ${ }^{18}$ Consequently, $\mathrm{MD}$ measures appear to be more sensitive for detecting microstructural progressive changes at later MS disease stages compared with FA measures. ${ }^{19}$

On the other hand, FA differences between early and chronic MS could also result from the evaluation of particular CST segments. In early MS, CST alterations have mainly been found in the internal capsule segments of the tract, whereas in chronic disease stages, periventricular CST has been investigated instead. ${ }^{17,19}$ In general, within periventricular regions and the centrum semiovale, the FA values for the CST are lower as a result of fiber dispersion and the vicinity of the CST to gray matter or CSF. ${ }^{17}$ By contrast, CST bundles reaching from the internal capsule to the brainstem (as investigated here) are quite densely packed (indicating a high degree of myelination and axonal density), resulting in high FA measures. ${ }^{15}$ Disease-related FA alterations/gradients should, therefore, be much more easily detectable in the latter CST segments, characterized by high anisotropy; this aspect could additionally account for the relationship found between FA alterations and early disease stages. ${ }^{20}$

We documented CST FA and MD alterations not only within the WM lesions, but also within the normal-appearing WM segments. Such findings are in line with recent imaging studies, revealing widespread axonal pathology independent of MRI-visible lesions when applying $\mathrm{N}$-acetylaspartate MRI spectroscopy. ${ }^{21}$ FA and MD alterations in the NAWM thereby appear to precede the occurrence of contrast-enhancing inflammatory lesions. ${ }^{22}$ DTI alterations in this instance indicate early axonal swelling, oligodendrocyte stress, and apoptosis, as well as microglial clustering and activation. Subsequently, T-cell infiltration takes place, consistent with the underlying pathology found in contrast- 


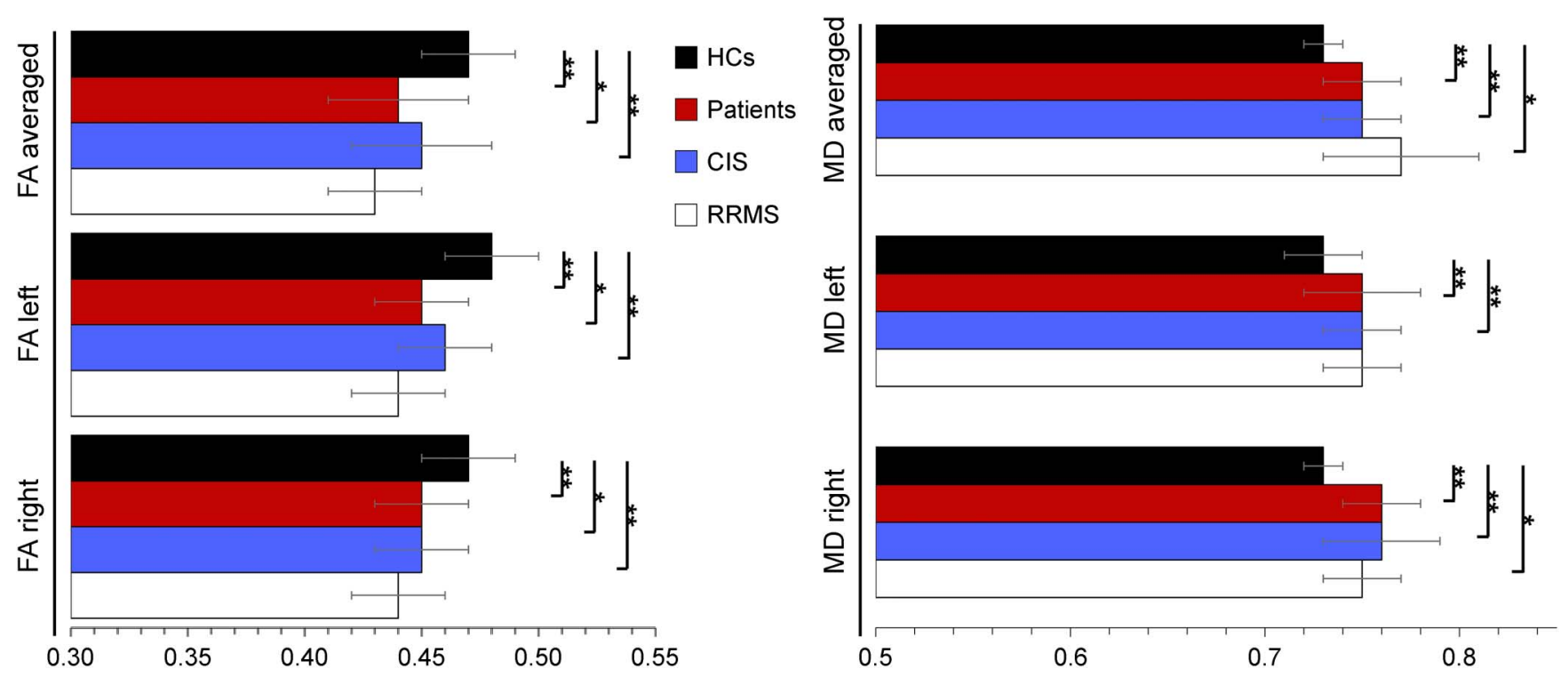

Means (horizontal bars) and standard deviations (whiskers) are given. $\mathrm{CIS}=$ clinically isolated syndrome; $\mathrm{HCs}=$ healthy controls; $\mathrm{FA}=$ fractional anisotropy; $\mathrm{MD}=$ mean diffusivity; RRMS = relapsing-remitting multiple sclerosis. $\mathrm{MD}$ is given in $\mathrm{mm}^{2} / \mathrm{s} * 10^{-3}$. $* \mathrm{P}<0.005 ; * * \mathrm{P}<0.001$.

enhancing lesions. ${ }^{23} \mathrm{FA}$ and MD values could thus serve as alternative markers of inflammation, probably indicating ongoing demyelination ${ }^{24}$ and predicting new relapses. ${ }^{25}$ DTI measures could thus have the potential to serve as a biomarker disclosing ongoing (inflammatory) disease activity, especially in secondary or primary progressive MS disease subtypes, which commonly do not present with contrast-enhancing lesions. ${ }^{26}$

In contrast to the group differences found when applying DTI measures, patients having early MS disease stages did not show overall gray or WM atrophy. These findings replicate previous results reporting unaltered overall brain volumes at initial disease stages. $^{27,28}$ Of interest, despite a lack of difference in total GMV between controls and patients with radiologically isolated syndrome (RIS) ${ }^{29}$ or CIS, ${ }^{28}$ both representing potentially early MS disease stages, regional subcortical volume loss has been observed, with reduced thalamic volume in both these groups. ${ }^{28,29}$ Regional volume differences were, however, not addressed in our study, and further investigations are required. Given that the reduced thalamic volume is observed in these early syndromes, and correlation reported between thalamic and WM lesion volumes was more modest in RIS $^{29}$

Figure 3 Comparison of diffusion values between corticospinal tracts (CST) of controls and CSTs of the patients not affected (naCST) or affected (aCST) by white matter lesions.
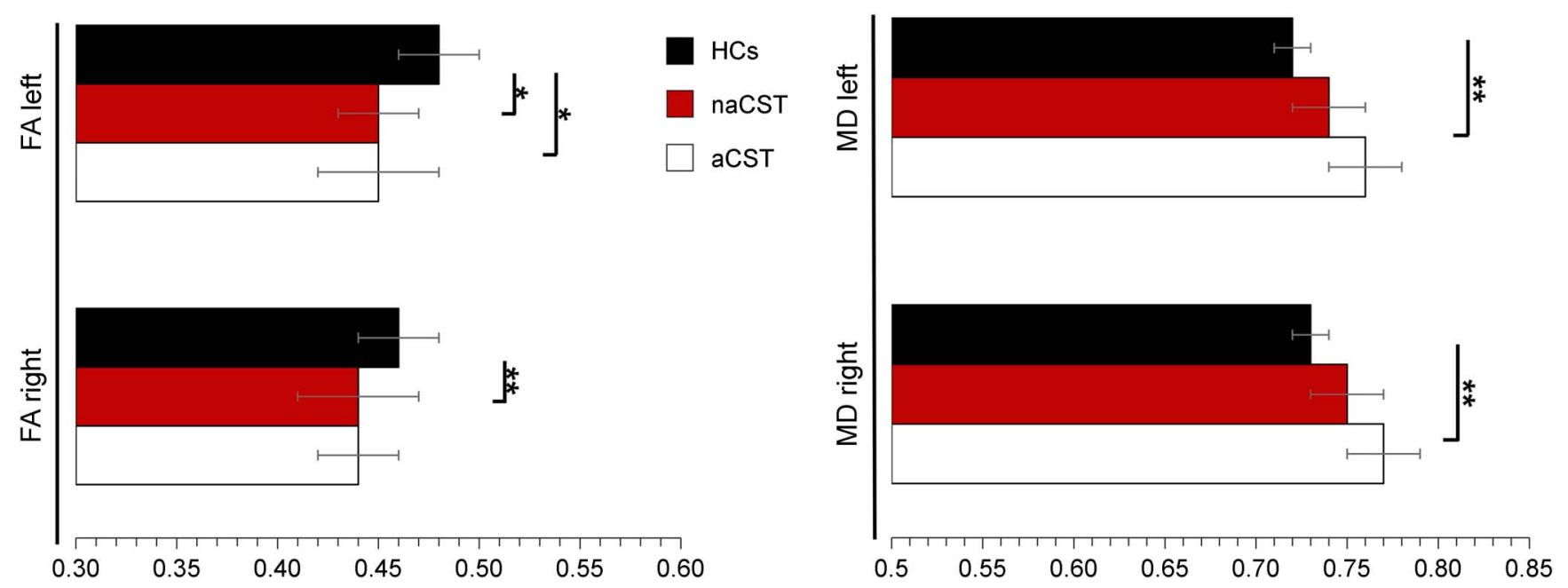

Means (horizontal bars) and standard deviations (whiskers) are given. $\mathrm{HCs}=$ healthy controls; $\mathrm{FA}=$ fractional anisotropy; $\mathrm{MD}=$ mean diffusivity. $\mathrm{MD}$ is given in $\mathrm{mm}^{2} / \mathrm{s} * 10^{-3}$. $\mathrm{P}<0.005 ; * \mathrm{P}<0.001$. 
than in CIS ${ }^{28}$ future work investigating a potentially stronger early correlation between DTI measures (CST FA and MD) and the thalamic volume may shed new light on the earliest WM changes in MS. Reduction of the whole-brain volume has been shown to take place over time, correlating with a clinical disease progression, ${ }^{30}$ when examining patients with (1) clinically definite $M S,{ }^{30}$ (2) presenting with higher median EDSS values, ${ }^{31}$ or (3) displaying longer mean disease durations of 1.8 years after symptom onset. ${ }^{32}$ In addition, with respect to long-standing MS, NAWM alterations have also been related to neuronal damage, i.e., deep gray matter and cortical atrophy. ${ }^{33}$ Patients with early disease stage MS displaying NAWM alterations in the face of (still) normal brain volume measures seem to be at a particular risk of later gray matter atrophy, associated with cognitive decline ${ }^{34}$ and related long-term disability. ${ }^{35}$ These findings overall emphasize the need for early identification of these cases (with NAWM alterations) to maintain their likely still intact gray matter structure. ${ }^{27}$

In routine clinical practice, patients with RRMS and CIS commonly display symptoms that should be unequivocally interpreted as a relapse, but in the case of absent underlying MRI lesions, neurologists often refrain from the necessary initiation of sufficient therapy. Early therapy initiation in CIS, however, reduces the patients' risk of MS conversion by $37 \%{ }^{36}$ Conversely, late therapy initiation is related to a greater likelihood of frequent relapse. ${ }^{37}$ Detection of NAWM alterations at early disease stages could overall result in a more rapid initiation of sufficient therapy, with avoidance of long-term disability.

RRMS and CIS cases displayed similar CST as well as white and GMVs, again replicating previous results. ${ }^{19,38}$ Disease severity assessed using the EDSS did not differ between disease groups, as also previously demonstrated. ${ }^{38}$ Nevertheless, compared with patients with CIS, patients with RRMS have frequently received disease-specific therapies, with the application of a wider range of new, disease-modifying drugs, resulting in significantly lower (1) annual relapse rates, (2) clinical disability, and (3) WM lesions and overall brain atrophy. ${ }^{39}$ On the other hand, patients with CIS left without disease-modifying therapy have been shown to develop rapidly progressive MRI changes. ${ }^{40}$ All these aspects imperatively argue for the application of similar therapeutic standards when handling patients with CIS and RRMS.

The strengths of our study comprise (1) the inclusion of patients with MS at very early disease stages, (2) the use of fiber tracking allowing differentiation between WM bundles affected or not affected by T2 or T1 lesions, and (3) the application of 3dimensional T1 images with a small slice thickness of $1.5 \mathrm{~mm}$, facilitating highly sensitive measurements (of, e.g., gray and WMVs). Limitations of the present study include relatively a small sample size, which did not allow the splitting of the cohort into CIS and RRMS case groups when analyzing DTI measures with the CST affected or not affected by WM lesions. An additional shortcoming is the absence of other measures of WM tracts (e.g., optic radiation and cerebellar connections), and further studies are needed. Long-term follow-up of these patients is required to evaluate the correlation between these DTI measures and clinical progression.

Our findings suggest that corticospinal motor system axonal integrity loss can also be detected in very early MS disease stages, even in the absence of WM lesions and before brain volume loss takes place. DTI measures may, therefore, be useful to guide and reinforce therapeutic decisions in cases displaying no or only few inflammatory lesions in the face of just 1 clinical event, with the hope of slowing disease progression and avoiding long-term disability in patients with MS. Future studies should moreover combine DTI, spectroscopy, PET, functional MRI, and CSF measures of, e.g., neurofilament, to better understand the underlying pathophysiology of early FA and MD alterations in NAWM.

\section{AUTHOR CONTRIBUTIONS}

Marc Pawlitzki has access to all the data and takes responsibility for the data, accuracy of the data analysis, the conduct of the research design and conceptualization of the study and analysis and interpretation of the data, and drafting the manuscript for intellectual content. Jens Neumann: design and conceptualization of the study and revising the manuscript for intellectual content. Jörn Kaufmann: accuracy of the data analysis, conduct of the research design analysis and interpretation of the data, and drafting the manuscript for intellectual content. Jan Heidel and Erhard Stadler: design and conceptualization of the study and revising the manuscript for intellectual content. Catherine Sweeney-Reed: design and conceptualization of the study and revising the manuscript for intellectual content and improvement of language. Michael Sailer: accuracy of the data analysis, the conduct of the research design analysis and interpretation of the data, and drafting the manuscript for intellectual content. Stefanie Schreiber has access to all the data and takes responsibility for the data, accuracy of the data analysis, and the conduct of the research design and conceptualization of the study and analysis and interpretation of the data and drafting the manuscript for intellectual content.

\section{STUDY FUNDING}

This work was supported by a grant to Stefanie Schreiber from the Otto von Guericke University Magdeburg (grant for Young Scientists 2016).

\section{DISCLOSURE}

M. Pawlitzki served on the scientific advisory board for Novartis, Merck Serono, and Genzyme and received travel funding from Merck Serono and Novartis. J. Neumann, J. Kaufmann, J. Heidel, E. Stadler, and C. Sweeney-Reed report no disclosures. M. Sailer received speaker honoraria from Bayer Vital, Genzyme, Sanofi Aventis Germany, and TEVA and research grants from Novartis, Merck Serono, and Bayer Vital. S. Schreiber received research support from Medical Faculty at the Otto von Guericke University in Magdeburg, German Research Foundation. Go to Neurology.org/nn for full disclosure forms.

Received June 10, 2017. Accepted in final form August 8, 2017.

\section{REFERENCES}

1. Compston A, Coles A. Multiple sclerosis. Lancet 2008; 372:1502-1517. 
2. Barkhof $\mathrm{F}$. The clinico-radiological paradox in multiple sclerosis revisited. Curr Opin Neurol 2002;15: 239-245.

3. Trapp BD, Peterson J, Ransohoff RM, Rudick R, Mörk S, Bö L. Axonal transection in the lesions of multiple sclerosis. N Engl J Med 1998;338:278-285.

4. Jonkman LE, Soriano AL, Amor S, et al. Can MS lesion stages be distinguished with MRI? A postmortem MRI and histopathology study. J Neurol 2015; 262:1074-1080.

5. Seewann A, Vrenken H, van der Valk P, et al. Diffusely abnormal white matter in chronic multiple sclerosis: imaging and histopathologic analysis. Arch Neurol 2009;66:601-609.

6. Kappos L, de Stefano N, Freedman MS, et al. Inclusion of brain volume loss in a revised measure of "no evidence of disease activity" (NEDA-4) in relapsing-remitting multiple sclerosis. Mult Scler 2016;22:1297-1305.

7. McDonald WI, Compston A, Edan G, et al. Recommended diagnostic criteria for multiple sclerosis: guidelines from the International Panel on the diagnosis of multiple sclerosis. Ann Neurol 2001;50:121-127.

8. Kurtzke JF. Rating neurologic impairment in multiple sclerosis: an expanded disability status scale (EDSS). Neurology 1983;33:1444-1452.

9. Bodammer NC, Kaufmann J, Kanowski M, Tempelmann C. Monte Carlo-based diffusion tensor tractography with a geometrically corrected voxel-centre connecting method. Phys Med Biol 2009;54:1009-1033.

10. Reich DS, Smith SA, Jones CK, et al. Quantitative characterization of the corticospinal tract at 3T. AJNR Am J Neuroradiol 2006;27:2168-2178.

11. Beer A, Biberacher V, Schmidt P, et al. Tissue damage within normal appearing white matter in early multiple sclerosis: assessment by the ratio of T1- and T2-weighted MR image intensity. J Neurol 2016;263:1495-1502.

12. Vishwas MS, Healy BC, Pienaar R, Gorman MP, Grant $\mathrm{PE}$, Chitnis T. Diffusion tensor analysis of pediatric multiple sclerosis and clinically isolated syndromes. AJNR Am J Neuroradiol 2013;34:417-423.

13. Harrison DM, Caffo BS, Shiee N, et al. Longitudinal changes in diffusion tensor-based quantitative MRI in multiple sclerosis. Neurology 2011;76:179-186.

14. Tortorella P, Rocca MA, Mezzapesa DM, et al. MRI quantification of gray and white matter damage in patients with early-onset multiple sclerosis. J Neurol 2006; 253:903-907.

15. Reich DS, Smith SA, Zackowski KM, et al. Multiparametric magnetic resonance imaging analysis of the corticospinal tract in multiple sclerosis. NeuroImage 2007; 38:271-279.

16. Kolasinski J, Stagg CJ, Chance SA, et al. A combined postmortem magnetic resonance imaging and quantitative histological study of multiple sclerosis pathology. Brain 2012 135:2938-2951.

17. Sbardella E, Tona F, Petsas N, Pantano P. DTI measurements in multiple sclerosis: evaluation of brain damage and clinical implications. Mult Scler Int 2013;2013: 671730.

18. Castriota-Scanderbeg A, Fasano F, Hagberg G, Nocentini U, Filippi M, Caltagirone C. Coefficient $\mathrm{D}(\mathrm{av})$ is more sensitive than fractional anisotropy in monitoring progression of irreversible tissue damage in focal nonactive multiple sclerosis lesions. AJNR Am J Neuroradiol 2003;24:663-670.
19. Natarajan R, Hagman S, Wu X, et al. Diffusion tensor imaging in NAWM and NADGM in MS and CIS: association with candidate biomarkers in Sera. Mult Scler Int 2013;2013:265259.

20. Lin F, Yu C, Jiang T, Li K, Chan P. Diffusion tensor tractography-based group mapping of the pyramidal tract in relapsing-remitting multiple sclerosis patients. AJNR Am J Neuroradiol 2007;28:278-282.

21. Filippi M, Bozzali M, Rovaris M, et al. Evidence for widespread axonal damage at the earliest clinical stage of multiple sclerosis. Brain 2003;126:433-437.

22. Ontaneda D, Sakaie K, Lin J, et al. Identifying the start of multiple sclerosis injury: a serial DTI study. J Neuroimaging 2014;24:569-576.

23. van der Valk P, Amor S. Preactive lesions in multiple sclerosis. Curr Opin Neurol 2009;22:207-213.

24. Werring DJ. The pathogenesis of lesions and normalappearing white matter changes in multiple sclerosis: a serial diffusion MRI study. Brain 2000;123: 1667-1676.

25. Cramer SP, Simonsen H, Frederiksen JL, Rostrup E, Larsson HBW. Abnormal blood-brain barrier permeability in normal appearing white matter in multiple sclerosis investigated by MRI. Neuroimage Clin 2014; 4:182-189.

26. Shirani A, Okuda DT, Stüve O. Therapeutic advances and future prospects in progressive forms of multiple sclerosis. Neurotherapeutics 2016;13:58-69.

27. Raz E, Cercignani M, Sbardella E, et al. Gray- and whitematter changes 1 year after first clinical episode of multiple sclerosis: MR imaging. Radiology 2010;257:448-454.

28. Henry RG, Shieh M, Okuda DT, Evangelista A, GornoTempini ML, Pelletier D. Regional grey matter atrophy in clinically isolated syndromes at presentation. J Neurol Neurosurg Psychiatry 2008;79:1236-1244.

29. Azevedo CJ, Overton E, Khadka S, et al. Early CNS neurodegeneration in radiologically isolated syndrome. Neurol Neuroimmunol Neuroinflamm 2015;2:e102. doi: 10. 1212/NXI.0000000000000102.

30. Pérez-Miralles FC, Sastre-Garriga J, Vidal-Jordana A, et al. Predictive value of early brain atrophy on response in patients treated with interferon $\beta$. Neurol Neuroimmunol Neuroinflamm 2015;2:e132. doi: 10.1212/NXI.0000000000000132.

31. Vågberg $\mathrm{M}$, Lindqvist $\mathrm{T}$, Ambarki $\mathrm{K}$, et al. Automated determination of brain parenchymal fraction in multiple sclerosis. AJNR Am J Neuroradiol 2013;34: 498-504.

32. Chard DT, Griffin CM, Parker GJM, Kapoor R, Thompson $\mathrm{AJ}$, Miller DH. Brain atrophy in clinically early relapsingremitting multiple sclerosis. Brain 2002;125:327-337.

33. Steenwijk MD, Daams M, Pouwels PJ, et al. What explains gray matter atrophy in long-standing multiple sclerosis? Radiology 2014;272:832-842.

34. Summers M, Fisniku L, Anderson V, Miller D, Cipolotti L, Ron M. Cognitive impairment in relapsing-remitting multiple sclerosis can be predicted by imaging performed several years earlier. Mult Scler 2008;14:197-204.

35. Popescu V, Agosta F, Hulst HE, et al; MAGNIMS Study Group. Brain atrophy and lesion load predict long term disability in multiple sclerosis. J Neurol Neurosurg Psychiatry 2013;84:1082-1091.

36. Kappos L, Freedman MS, Polman CH, et al; BENEFIT Study Group. Long-term effect of early treatment with interferon beta- $1 \mathrm{~b}$ after a first clinical event suggestive 
of multiple sclerosis: 5-year active treatment extension of the phase 3 BENEFIT trial. Lancet Neurol 2009;8: 987-997.

37. Corvino FA, Oliveri D, Phillips AL. The association of timing of disease-modifying drug initiation and relapse in patients with multiple sclerosis using electronic health records. Curr Med Res Opin 2017;33:1-14.

38. Disanto G, Benkert P, Lorscheider J, et al; SMSC Scientific Board. The Swiss Multiple Sclerosis Cohort-Study (SMSC): a prospective Swiss wide investigation of key phases in disease evolution and new treatment options. PLoS One 2016;11:e0152347.

39. Fogarty E, Schmitz S, Tubridy N, Walsh C, Barry M. Comparative efficacy of disease-modifying therapies for patients with relapsing remitting multiple sclerosis: Systematic review and network meta-analysis. Mult Scler Relat Disord 2016;9:23-30.

40. CHAMPS Study Group. MRI predictors of early conversion to clinically definite MS in the CHAMPS placebo group. Neurology 2002;59:998-1005. 


\title{
Neurology \\ Neuroimmunology \& Neuroinflammation
}

\author{
Loss of corticospinal tract integrity in early MS disease stages \\ Marc Pawlitzki, Jens Neumann, Jörn Kaufmann, et al. \\ Neurol Neuroimmunol Neuroinflamm 2017;4; \\ DOI 10.1212/NXI.0000000000000399
}

This information is current as of September 25, 2017

\section{Updated Information \& Services \\ Supplementary Material}

References

Subspecialty Collections

Permissions \& Licensing

Reprints including high resolution figures, can be found at:

http://nn.neurology.org/content/4/6/e399.full.html

Supplementary material can be found at:

http://nn.neurology.org/content/suppl/2017/09/25/4.6.e399.DC1

This article cites 40 articles, 5 of which you can access for free at: http://nn.neurology.org/content/4/6/e399.full.html\#\#ref-list-1

This article, along with others on similar topics, appears in the following collection(s):

DWI

http://nn.neurology.org//cgi/collection/dwi

MRI

http://nn.neurology.org//cgi/collection/mri

Multiple sclerosis

http://nn.neurology.org//cgi/collection/multiple_sclerosis

Information about reproducing this article in parts (figures,tables) or in its entirety can be found online at:

http://nn.neurology.org/misc/about.xhtml\#permissions

Information about ordering reprints can be found online:

http://nn.neurology.org/misc/addir.xhtml\#reprintsus

Neurol Neuroimmunol Neuroinflamm is an official journal of the American Academy of Neurology.

Published since April 2014, it is an open-access, online-only, continuous publication journal. Copyright

Copyright (C) 2017 The Author(s). Published by Wolters Kluwer Health, Inc. on behalf of the American

Academy of Neurology.. All rights reserved. Online ISSN: 2332-7812.

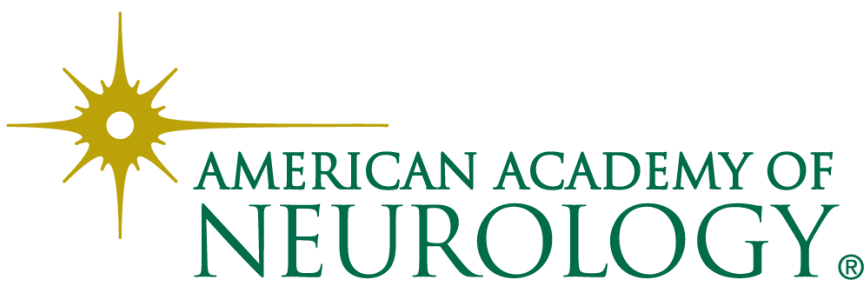

